\title{
Effect of Preloading on Local Residual Stresses Induced by Laser Surface Hardening of Steel
}

\author{
Vladimir Kostov ${ }^{1, a}$, Jens Gibmeier ${ }^{1, b}$, Klaudia Lichtenberg ${ }^{1, \mathrm{c}}$ and \\ Alexander Wanner ${ }^{1, d}$ \\ ${ }^{1}$ Karlsruhe Institute of Technology (KIT), Institute for Applied Materials (IAM), Kaiserstrasse 12, \\ D-76131 Karlsruhe, Germany \\ a vladimir.kostov@kit.edu, bjens.gibmeier@kit.edu, ' klaudia.lichtenberg@kit.edu, \\ dalexander.wanner@kit.edu
}

Keywords: laser surface hardening, bending load, in-situ X-ray stress analysis, steel AISI 4140, preloading

\begin{abstract}
The effect of defined preloading in the tensile and compressive regime on the near surface (residual) stress distributions, which result from laser surface hardening, is systematically studied in-situ, i.e. under the applied preload and after unloading. Samples made of steel grade AISI 4140 are defined surface hardened by means of a high-power diode laser (HPDL) system during uniaxial compressive elastic loading at $-300 \mathrm{MPa}$ as well as during uniaxial elastic tensile loading at $300 \mathrm{MPa}$ using a custom designed 4-point-bending device, which can be mounted on an X-ray diffractometer. The results of X-ray stress analysis were compared to data derived for a sample state unaffected by any preload. Without external loading compressive residual stresses are induced inside the process zone that are balanced by tensile residual stresses outside this zone. The investigations show that external loading in the tensile and compressive regime has a strong impact on the resulting lateral residual stress distribution in loading direction. The results further indicate that undesirable tensile residual stresses outside the process zone can even be suppressed by using a defined appropriate preloading in the tensile regime.
\end{abstract}

\section{Introduction}

Thermal as well as thermo-mechanical processes exhibit an enormous technical and economic importance for surface optimization for improvement of the surface integrity, since most degradation processes like e.g. corrosion or crack initiation have their origin at the very surface of technical components. Laser surface hardening of steel is superior to other local-acting surface hardening processes for the application on complex shaped parts, where contour aligned martensitic hardening is required. Further, laser surface hardening offers a higher precision and causes less distortion than other local-acting surface hardening techniques, like flame hardening or induction hardening [1]. Although the laser surface hardening is a rather complex process, it can be considered as a standard heat treatment technique aiming to improve the mechanical behavior of steel components, with a good acceptance in the industry. Using an appropriate hardening optics in combination with a high power laser system localized phase transformations are provoked with very fast local heating into the austenite regime followed by a laser controlled self-quenching. The selfquenching is supported by conduction of the heat into the cold material that surrounds the process zone to form martensite. This local transformation is accompanied by characteristic residual stress distributions with compressive residual stresses directly in the process zone, which are balanced by tensile residual stresses outside of the laser processed material volume [1-3]. In general, these tensile residual stresses are undesired; hence they promote the initiation of fatigue cracks at the top surface of structural component during operation and thus they provoke premature failure. Process optimization also addresses the optimization of the induced residual stresses (e. g. [2,3,5]). A good compromise between sufficiently high compressive residual stresses and balancing tensile residual stresses must be sought. For other surface optimization processes, like e.g. for shot peening the 
mitigation of undesired tensile residual stresses was achieved by applying shot peening under defined tensile preloads of steel samples [4]. In the present studies on laser surface hardening we have adapted this approach. Hence, laser surface hardening under predefined bending loads was carried out and the near surface stress distribution was determined in-situ, i.e. under the acting preload by means of X-ray stress analysis. Further, the residual stress distributions that result after releasing the preload were determined. The results are compared with results of investigations carried out for temperature controlled laser surface hardening without external preloading.

\section{Experimental setup}

As work-piece material low alloyed heat treatable steel AISI 4140 (German grade 42CrMo4) was chosen. The sample dimension was $160 \times 20 \times 10 \mathrm{~mm}^{3}$. Prior to the in-situ diffraction analyses the bending bars were quenched and tempered, mechanically ground and afterwards subjected to a stress relieve heat treatment. Using a self-constructed 4-point bending device with a distance between the inner supports of $50 \mathrm{~mm}$, which was designed that it can be mounted on the X-ray diffractometer, the bending bars were defined uniaxially loaded in the elastic regime. The laser hardening was applied on the tensile loaded or on the compressive loaded side of the bar. The loading was controlled by measuring the strain in the outer fibers by using strain gauges that were applied on the tensile and on the compressive loaded side. Using a calibration test performed on a universal testing machine in combination with the bending loading device, the bending bars were subjected to defined elastic loading stresses in the outer fibers of $-300 \mathrm{MPa}, 0 \mathrm{MPa}$ and $+300 \mathrm{MPa}$ during laser processing.

The laser processing was carried out using a high power diode laser (HLDL) system of type VDL 400 from Laserline GmbH, Mülheim-Kärlich, Germany and a homogenizing optic with a nominal focal spot size of $8 \times 8 \mathrm{~mm}^{2}$. Temperature controlled hardening was conducted by means of a twocolor pyrometer from Mergentaler $\mathrm{GmbH}$, Germany and the control software Lascon. As process parameters a defined heating / cooling rate of $\mathrm{V}_{\text {heating/cooling }}=1000 \mathrm{~K} / \mathrm{s}$ and a control temperature for austenitization of $\mathrm{T}_{\mathrm{A}, \max }=1150{ }^{\circ} \mathrm{C}$ were applied. The laser surface hardening was carried out using a self-designed process chamber, which is required for the reproducible processing under oxygen free atmosphere [3] and for radiation protection. The chamber was already presented in [6]; the setup is displayed in Fig. 1. The bending bars mounted in the bending device were introduced to the chamber, which was subsequently evacuated and filled with Helium gas at a pressure of 1,25 mbar. The laser and the pyrometer radiation were coupled in/out to/from the chamber using specially coated windows.
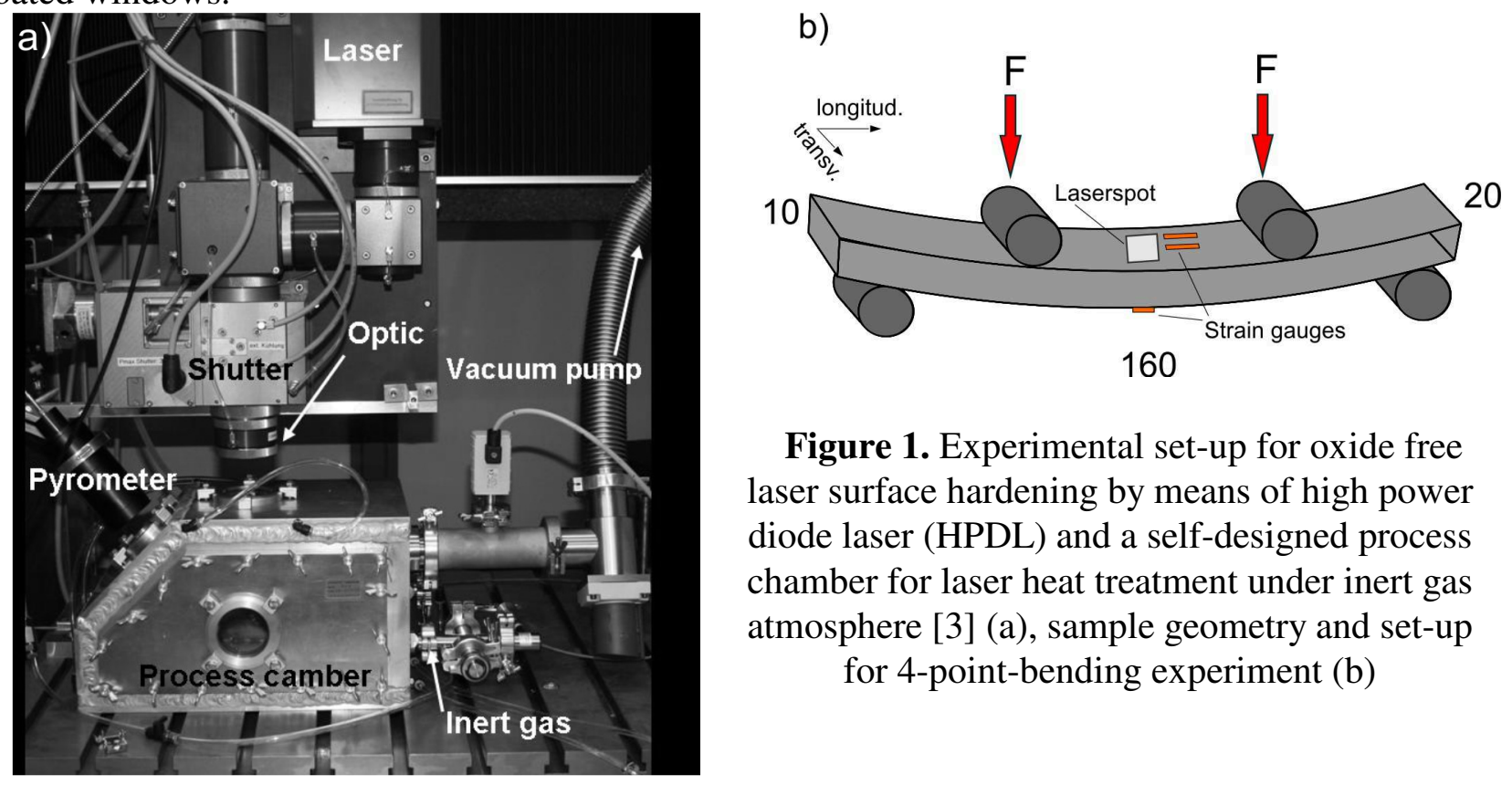

Figure 1. Experimental set-up for oxide free laser surface hardening by means of high power diode laser (HPDL) and a self-designed process chamber for laser heat treatment under inert gas atmosphere [3] (a), sample geometry and set-up for 4-point-bending experiment (b) 
After defined laser processing the (residual) stresses were analyzed (i) with the bending load still acting and (ii) for the unloaded state. The bending device was mounted on the diffractometer and Xray stress analysis was carried out according to the well-known $\sin ^{2} \psi$-method [7] using $\mathrm{Cr}-\mathrm{K} \alpha$ radiation and a $\mathrm{V}$-filter for $\mathrm{K} \beta$ suppression. The $\{211\}$-reflex of the ferrite/martensite phase was analyzed for tilt angles $-50.7^{\circ}<\psi<50.7^{\circ}$. Actually, this range was limited by the geometry of the loading device. As primary aperture a pinhole collimator with a nominal opening of $\varnothing 0.5 \mathrm{~mm}$ and a symmetrizing slit on the secondary side in front of the scintillation counter. The interference profiles were fitted using a Pearson VII - function. Additional to the stress measures the integral breadth IB of the X-ray interference profiles were determined, which can be considered as measures of the cold-working induced during the process. Complementary to X-ray stress analyses microstructural investigations as well as martens hardness tests [8] were carried out subsequent to X-ray residual stress analysis, i.e. after releasing the bending load. The Martens hardness studies were carried out on the carefully prepared cross sectional areas through the process zones using an instrumented micro hardness measurement system of type Fischerscope H100 (Helmut Fischer GmbH, Sindelfingen, Germany) equipped with a Vickers pyramid and using a nominal testing load of $300 \mathrm{mN}$.

\section{Results and Discussion}

In Figure 2a) the distribution of the martens hardness HM after unloading the laser surface hardened bending bars is shown vs. the distance to the center of the laser spot. Considering a better orientation of the laser hardened process zone and dimension, which is designated as PZ in correspondence to [6], has been also included.

a)

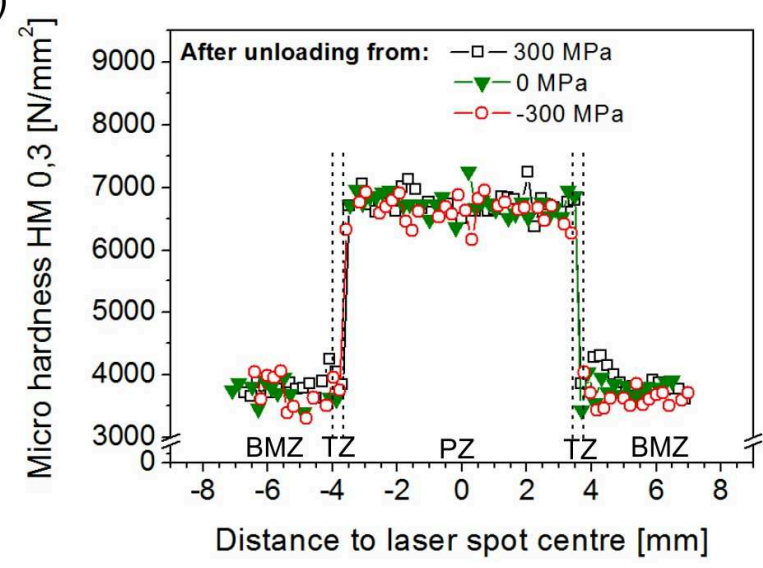

b)

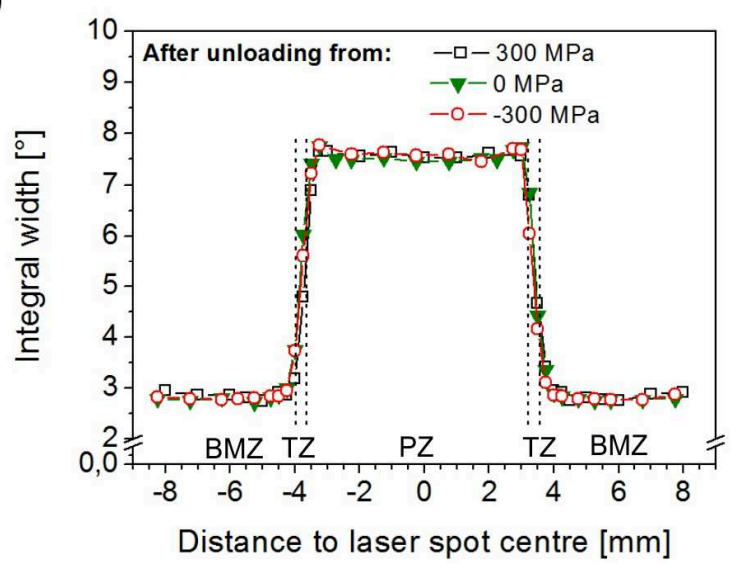

Figure 2. Distribution of the Martens hardness HM at the cross-sectional plane in lateral direction in a distance of $50 \mu \mathrm{m}$ to the surface (a) and integral width of the $\{211\}$-reflex inside and outside the process zone at the top surface (b) as function of the distance to laser spot center of samples hardened under acting preloading and corresponding distributions after unloading.

The data show a micro hardness distribution as characteristic for stationary laser hardening experiments, showing a plateau of the hardness values at around $7000 \mathrm{~N} / \mathrm{mm}^{2}$, which corresponds with the dimension of the process zone. In the narrow transition zone TZ between hardened material $\mathrm{PZ}$ and the base metal zone BMZ a sudden drop down of the Martens hardness can be observed (see also [6]) to a mean value of about $3700 \mathrm{~N} / \mathrm{mm}^{2}$, which characterizes the hardness level of the quenched and tempered base metal. Further, the data illustrate that the applied preload has no significant effect on the Martens hardness distributions. Within the measurement uncertainty of the micro hardness readings the hardness distributions can be considered to be equivalent. Also the 
lateral extension of the laser hardened process zone is unaffected by the preloading, which corresponds well with the microstructural investigation displayed in Figure 3. Here, micrographs recorded by means of light optical microscopy LOM are shown together with an overview of some measures characterizing the hardened lens. The results clearly show that the dimension of the martensitic hardened zone is unaffected by the applied preload.

a)

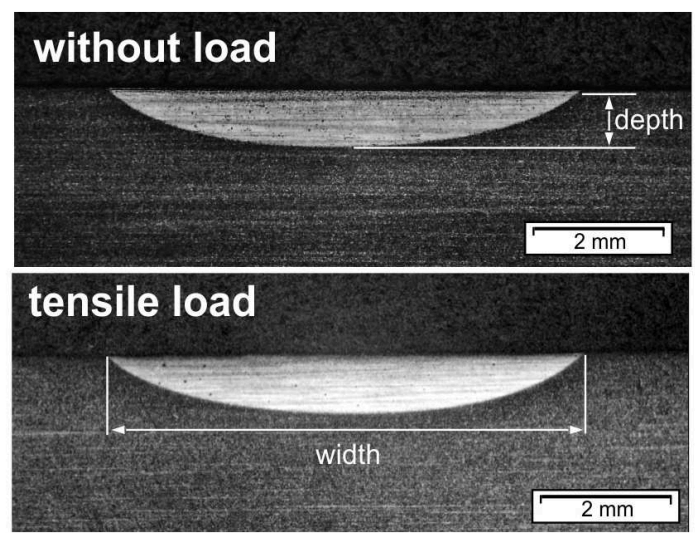

b)

\begin{tabular}{|c||c|c|c|}
\hline $\begin{array}{c}\text { hardened } \\
\text { zone }\end{array}$ & $\begin{array}{c}\text { without } \\
\text { load }\end{array}$ & tensile load & $\begin{array}{c}\text { compressive } \\
\text { load }\end{array}$ \\
\hline depth & $0,925 \mathrm{~mm}$ & $0,924 \mathrm{~mm}$ & $0,921 \mathrm{~mm}$ \\
\hline width & $7,170 \mathrm{~mm}$ & $7,231 \mathrm{~mm}$ & $7,171 \mathrm{~mm}$ \\
\hline
\end{tabular}

Figure 3. (a) Cross sectional micrographs of the laser surface hardened process zone without any preload (top) and for a tensile preloaded sample (bottom) with (b) an overview of the characteristic measures 'depth' and 'width' of the hardening lens extracted from the LOM images.

Figure $2 b$ displays the corresponding lateral distribution of the integral width IB of the X-ray interference profiles along the sample surface. The distribution correlates well with the microhardness distribution, as expected. Based on the results the bending loading stresses obviously do not have a significant effect on the resulting hardening state after unloading of the laser processed samples. However, it could be expected that an externally applied loading stress causes a change of the local yield stress and thus will result in a change of the work hardening behavior. Based on results of in-situ strain analysis during laser surface hardening presented in [9] the material in the process zone is plastically compressed and during subsequent cooling down plastically elongated, while the amount of plastic elongation strongly depends on the previous plastic compression before. Obviously, the concurring effects balance themselves in a way that in consequence no significant change in the work hardening behavior can be observed in comparison with the non-prestressed material state.

Laser surface hardening without any preloading of the materials volume results in a characteristic residual stress distribution in lateral direction at the surface with compressive residual stresses inside the process zone PZ, which are balanced by tensile residual stresses outside the process zone, i.e. in the base metal (see also [4,6]). Considering the (residual) stress distributions of the process variations with tensile or compressive preloads no significant changes occur for the lateral distribution in loading direction, which is the longitudinal direction of the bending bar (see Figure 4a), as long as the externally applied preload is still impressed. However, outside the process zone the effect of the loading stress increases continuously with increasing distance to the center of the laser spot.

After releasing the preload (see Figure 4c) a shift of the stress distribution about the amount of the preload can be observed. This leads to a shift of the entire stress distribution (in the PZ and in its vicinity) of the formerly compressive loaded states into the tensile regime and furthermore a shift of the formerly tensile loaded states towards the compression regime. In detail this means that for the laser processing using a compressive preload tensile residual stresses in the range between 150 $300 \mathrm{MPa}$ are determined around the center of the process zone, whereas for the samples subjected to 
an uniaxial tensile preload largely increased compressive residual stresses in the range of -350 up to about $-400 \mathrm{MPa}$ near to the laser spot center and peak values in the vicinity to the transition zone of more than about $-600 \mathrm{MPa}$. The entire lateral residual stress distribution is now shifted to the compressive regime. This shift can be explained by an elastic superposition of the process induced stress states with the applied preloads and is similar to the finding presented in [4] for shot peening under defined preloads. However, transverse to the loading direction almost no effect of the uniaxial preload on the resulting residual stress distribution can be noticed. Regardless of the preload the residual stress distributions are almost congruent, again with moderate compressive residual stresses in the process zone characterized by a plateau, which slightly increases towards the edge of the process zone and are balanced by tensile residual stresses outside the PZ.

Longitudinal (loading) direction

a)

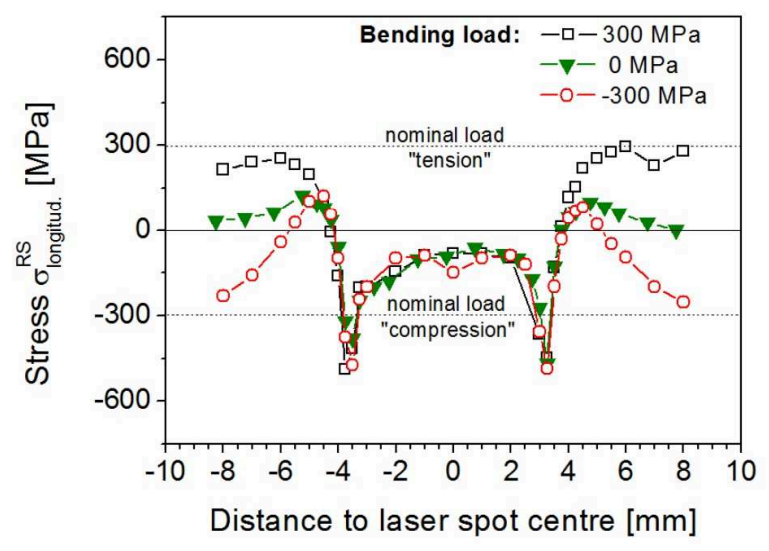

c)

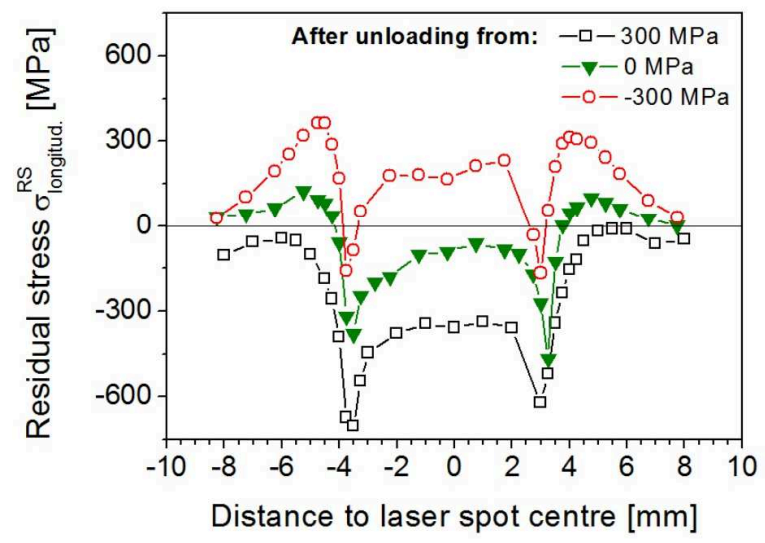

Transverse direction

b)

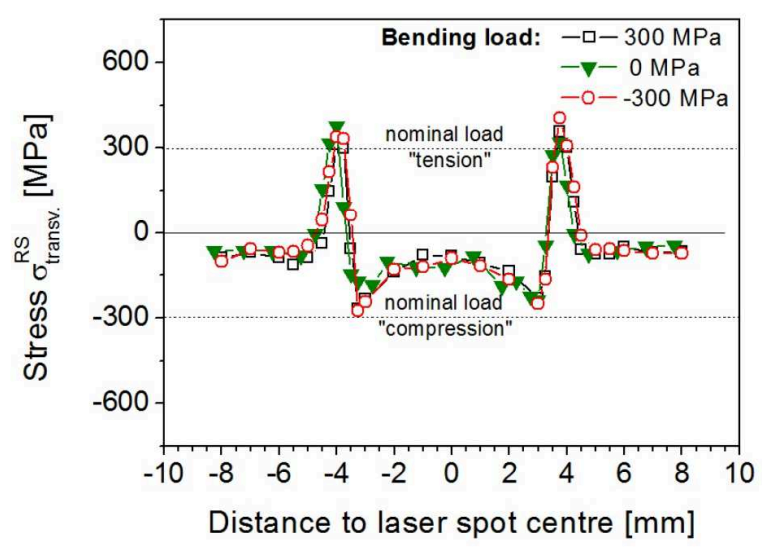

d)

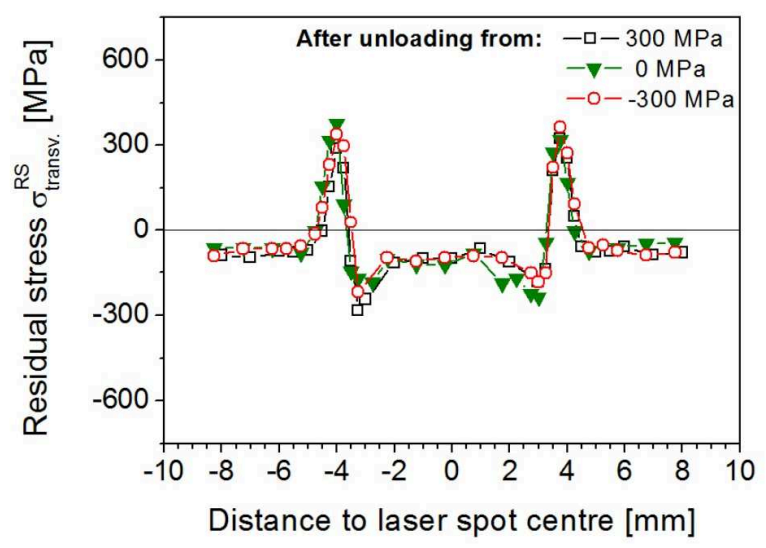

Figure 4. Lateral distribution of the stresses as function of the distance to laser spot center at the sample surface after laser hardening under bending in (a) longitudinal direction (loading direction) and (b) transverse direction (across the loading direction) as well as residual stress distribution after unloading in (c) longitudinal direction and (d) transverse direction.

\section{Summary}

Stationary laser surface hardening on quenched and tempered steel type AISI 4140 was carried out for samples, which were subjected to purely elastic preload by means of 4-point-bending in the tension and compression regime. The results illustrate that the dimension as well as the microstructure of the locally martensitic hardened zone is almost unaffected by the herein applied bending load. Further, after unloading of the beforehand preloaded samples the lateral residual 
stress distribution at the laser surface hardened sample was strongly affected by the preload during laser processing. The residual stress distribution was shifted in correspondence to the released bending preload towards the tensile regime for formerly compressively preloaded samples and towards the compressive loaded regime in case of the previously tensile loaded samples, which is due to elastic superposition of processing induced stresses and the applied preload. A tensile preload of $300 \mathrm{MPa}$ during laser hardening results in a prevention of any tensile residual stresses in loading direction around the transition zone between martensitic hardened material and base metal. In the direction transverse to the load no significant effect of the preload can be noticed on basis of the experimental results. Hence, like proposed for shot peening under defined preloads, elastic tensile prestressing of the samples or components can successfully be applied to mitigate detrimental processing induced tensile residual stresses.

\section{Acknowledgements}

Financial support by the German 'Federal Ministry of Education and Research' (BMBF) through project number 05K10VKA and by the German Research Foundation through project number GI 376/5-1 is gratefully acknowledged.

\section{References}

[1] J.C. Ion: Laser transformation hardening, Surface Engineering, 18 (2002) 14-31

[2] J. Domes: Die Ausbildung von Makroeigenspannungen beim Laserrandschichthärten und anderen Verfahren der Lasermaterialbearbeitung, Doctorate thesis, Universität ErlangenNürnberg, 1995

[3] V. Kostov, J. Gibmeier, A. Wanner: Laser surface hardening of steel: Effect of the process atmosphere on the microstructure and residual stress, Mater Sci. Forum, 772 (2014), 149-153

[4] A. Wick: Randschichtzustand und Schwingfestigkeit von 42 CrMo 4 nach Kugelstrahlen unter Vorspannung und bei erhöhter Temperatur, Shaker Verlag, ISBN: 3-8265-6777-3, 1999

[5] H. W. Bergmann, E. Geissler: Laserhärten von Stählen, HTM, 46, (1991), 91-96

[6] V. Kostov, J. Gibmeier, A. Wanner: Local residual stress distribution induced by repeated austenite-martensite transformation via laser surface hardening of steal AISI 4140, Mater. Sci. Forum 681, (2011), 321-326

[7] E. Macherauch, P. Müller: Das $\sin ^{2} \psi$-Verfahren der röntgenographischen Spannungsmessung, Z. angew. Physik, 13 (1961) 305-312

[8] DIN EN ISO 14577, Beuth Verlag, Berlin (2003)

[9] V. Kostov, J. Gibmeier, F. Wilde, P. Staron, R. Rößler and A. Wanner: Fast in-situ phase and stress analyses during laser surface treatment - A synchrotron X-ray diffraction approach, Rev of Sci. Instrum., 83, 115101 (2012) 